\title{
A teoria reconstrutiva do direito. Notas sobre a gênese lógica do sistema dos direitos fundamentais em Habermas
}

\author{
Luiz Repa \\ luizrepa@uol.com.br \\ Universidade Federal do Paraná, Curitiba, Paraná, Brasil
}

\begin{abstract}
resumo Nesse artigo procuro mostrar que a reconstrução habermasiana da gênese lógica do sistema de direitos é uma tentativa de explicitar o significado da práxis constituinte, reduzindo-a a dois elementos, o princípio do discurso e o conceito de forma jurídica. 0 princípio do discurso pode ser objeto de uma reconstrução interna, pela qual os participantes da práxis deliberativa podem reconhecê-lo como imanente a essa práxis. Isso porque o princípio do discurso se assenta nos pressupostos da socialização lingüística em geral. 0 mesmo não se passa com a forma jurídica, que não pode ser derivada das condições comunicativas da linguagem e precisa de uma reconstrução de outro tipo, própria de uma teoria da evolução social.
\end{abstract}

palavras-chave Habermas; direitos fundamentais; reconstrução; teoria da modernidade

A gênese lógica dos direitos fundamentais, apresentada por Habermas no terceiro capítulo de Facticidade e validade, constitui o núcleo de sua teoria reconstrutiva do direito. É por meio dela que se pode elucidar como "o surgimento da legitimidade a partir a legalidade" não é, em si mesmo, um paradoxo (HABERMAS, 1994, p. 165). Com isso se esclarece também a relação fundamental de facticidade e validade, de direito positivo e democracia. A legitimidade pode surgir da legalidade, na medida em que esta se configura como um procedimento de criação do direito positivo que garante tanto a autonomia privada, os direitos subjetivos de ação, e a autonomia pública, os direitos políticos de participação no processo de formação da opinião e da vontade. 
Contudo, em que pese tal centralidade, a reconstrução do sistema de direitos, apresentada na gênese lógica, tem sido objeto de interpretações as mais distintas e mesmo contraditórias. Enquanto Habermas quer garantir e enfatizar a co-originariedade entre autonomia privada e autonomia pública, entre direitos humanos e soberania popular, os críticos ora se fincam em um aspecto ora em outro. Ora se critica o suposto viés liberal, ligado à tradição do direito natural, o que significaria uma subordinação da soberania popular aos direitos subjetivos à liberdade, justificados de um ponto de vista moral (Cf. KUPKA, 1994, SCHEUERMAN, 2002). Ora se critica o primado da soberania popular sobre os direitos humanos, de modo que os direitos subjetivos ficam inteiramente submetidos, em última instância, à vontade do legislador (LARMORE, 1993). Em geral essas leituras, que criticam o republicanismo a partir do liberalismo, ou vice-versa, ignoram a própria lógica da gênese lógica do sistema de direitos. A exceção fica por conta das contribuições de Ingeborg Maus e Klaus Günther, as quais têm sido desenvolvidas, no Brasil, por Rúrion Soares Mello e Felipe Gonçalves. Essas contribuições permitem entender, também de um ponto de vista metodológico, a co-originariedade de autonomia pública e privada e a reflexividade própria do direito moderno ${ }^{1}$.

Em conexão com essas contribuições mencionadas por último, gostaria de desenvolver aqui uma hipótese metodológica sobre a razão pela qual a exposição da gênese lógica tem de começar pelas categorias jurídicas de liberdade de ação. A gênese lógica em si mesma se alicerça em uma reconstrução horizontal de duplo vetor, de tal sorte que nas condições de possibilidade da soberania popular se encontram os direitos subjetivos de liberdade, e nas condições de possibilidade dos direitos subjetivos de liberdade, encontram-se os direitos de participação. Porém, tal reconstrução "horizontal” pressupõe uma "vertical”, isto é, própria de uma teoria da evolução social, destinada a decifrar o papel da forma direito para a integração social. A conexão dessas duas linhas reconstrutivas, horizontal e vertical, deve elucidar por que Habermas começa sua exposição da gênese lógica a partir dos direitos subjetivos à liberdade. A forma direito não pode ser derivada das estruturas lingüísticas imanentes à práxis de autolegislação, e, portanto, exige uma elucidação prévia e externa, que depois é internalizada por essa práxis. 
Em um primeiro momento, atenho-me ao núcleo da reconstrução evolutiva da forma direito e das relações funcionais entre ela e a moral. Em seguida, abordarei a gênese lógica propriamente dita, apontando o significado da co-originariedade e a lógica circular da exposição.

\section{I}

Apesar de o conceito kantiano de legalidade expressar, para Habermas, as características essenciais do direito positivo moderno, na medida em que combina coerção e liberdade, a teoria reconstrutiva do direito ainda enxerga aí uma fundamentação moral que não faz jus às condições póstradicionais de justificação de normas jurídicas, nem ao aspecto democrático radical de uma autolegislação de cidadãos. Como paradigmático da tradição do direito natural liberal, a filosofia kantiana do direito ainda submete a legalidade ao princípio moral do imperativo categórico. Daí resultaria uma subordinação do direito à moral, que não seria compatível "com a idéia de uma autonomia realizada no medium do próprio direito" (HABERMAS, 1994, p. 153).

Não se trata, com isso, de recusar uma relação entre moral e direito, pois este só pode ter legitimidade se não ferir princípios morais. Porém, daí não se pode derivar uma hierarquia entre normas morais e jurídicas, visto que tal concepção significaria escapar do horizonte de uma sociedade moderna racionalizada. Tal hierarquia é vista por Habermas como pertencente ao "mundo do direito pré-moderno". Em vez de uma hierarquia, a autonomia moral e o direito positivo devem encontrar-se em "uma relação de complementação" (HABERMAS, 1994, p. 137).

Tal relação de complementação só pode ser entendida, por sua vez, de um ponto de vista sociológico, isto é, desde o ponto de vista de uma reconstrução da evolução social. Desse ponto de vista, a forma direito [Rechtsform] apresenta-se como uma invenção necessária, destinada à resolução de desafios para integração social no contexto da emergência das sociedades modernas. Trata-se de uma explicação que elucida a forma direito em função de sua complementação com a moral, mas que detém especificidades próprias que não podem ser fundamentadas moralmente. Essas se devem, em última instância, ao 


\section{4}

caráter institucional do direito, que ao mesmo tempo coage e libera um espaço de manobra para ações estratégicas.

De um ponto de vista sociológico, a moral e o direito se diferenciam radicalmente por seus papéis e estruturas, pois, enquanto a moral póstradicional representa apenas "uma forma de saber cultural", o direito positivo constitui, além disso, "um sistema de ação, dotado de obrigatoriedade no nível institucional” (HABERMAS, 1994, p. 137). A relação de complementação só pode ser pensada, nesse caso, como uma relação funcional. A isso corresponde a afirmação - que está longe de ser pacífi$\mathrm{ca}$ - segundo a qual "a forma direito não é de modo algum um princípio que se possa 'fundamentar' seja epistêmica seja normativamente" (HABERMAS, 1994, p. 143; cf. PINZANI, 2000 e 2001).

Deixando de lado o que possa ser uma fundamentação "epistêmica", Habermas descarta a possibilidade de uma fundamentação normativa da direito devido às suas características formais básicas, extraídas do conceito kantiano de legalidade. Ou seja, a relação jurídica não leva em conta a capacidade das pessoas em ligar sua vontade por meio de idéias normativas, mas apenas sua capacidade de tomar decisões racionais com respeito a fins, isto é, a liberdade de arbítrio (HABERMAS, 1994, p. 144). Dessa redução da vontade livre que se autodetermina moralmente à sua liberdade de arbítrio, deriva, além disso, a delimitação da forma jurídica às condições externas da ação e a exclusão do caráter da motivação, moral ou estratégica, detendo-se apenas na conformidade à regra. Além disso, a liberação do arbítrio dos atores seria o "verso da medalha" do caráter coercitivo de leis que limitam os espaços de ação a partir de fora.

Todas essas características formais do direito positivo impedem uma fundamentação normativa que, para Habermas, só seria possível, no contexto das sociedades modernas, pela normatividade inerente aos pressupostos lingüísticos do discurso. Soma-se a isso o próprio fato de a forma direito ser uma invenção evolutiva da sociedade. Enquanto tal, não está excluída a possibilidade de nova invenção, colocando alternativas àquela do direito positivo moderno. $\mathrm{O}$ fato de Habermas reconstruir tão somente o direito positivo moderno se deve à impossibilidade de encontrar alternativas a ele no contexto das sociedades modernas, conforme sua teoria da evolução social2. 
O desafio evolutivo que a forma direito teve de resolver se refere, como já mencionado, à integração social. Tal desafio resulta do processo de racionalização que vai dissolvendo o poder integrador das visões religiosas e metafísicas do mundo, própria das sociedades tradicionais. Se de um lado isso supõe a liberalização cada vez maior dos potenciais de racionalidade inscritos na linguagem, de outro lado, acarreta também um maior dispêndio de energias para a busca cooperativa de acordos. De modo geral, surge para a integração da sociedade uma dependência de procedimentos formais, em última instância discursivos, para estabelecer normas legítimas, já que não se pode mais apelar para os costumes, para o ethos de uma determinada forma de vida em particular. Com isso, aumenta também "o risco de dissenso nas tomadas de posição de sim/não" em relação à validade das normas de ação em geral (HABERMAS, 1994, p. 42).

E junto como o risco de dissenso aumentam também as chances de as tentativas de ação orientada ao entendimento mútuo, isto é, as ações comunicativas, cederem às tentativas de ação estratégica, voltada unicamente para o êxito. E isso não só porque se intensifica a sobrecarga de realizações comunicativas a serem feitas em contextos de mundos da vida já inteiramente racionalizados e desencantados, de modo que surge uma gama enorme de confrontos de natureza bastante diversa, boa parte relativos a um embate de formas de vida variadas. Tal racionalização envolve também uma diferenciação cada vez maior entre esferas de ação orientada ao entendimento e ao êxito, as quais se encontravam entretecidas nas sociedades tradicionais. Daí surge o desafio estrutural para a integração social: "como integrar socialmente mundos da vida diferenciados (...) uma vez que cresce simultaneamente o risco de dissenso nos domínios da ação comunicativa, desligada de autoridades sagradas e de fortes instituições” (HABERMAS, 1994, p. 46), e mais precisamente em mundos da vida nos quais os agentes estão sempre diante da alternativa de agir estrategicamente.

A saída para esse problema seria então a "regulamentação normativa de interações estratégicas, sobre a qual os próprios atores se entendem" (HABERMAS, 1994, p. 44). Ou seja, o direito moderno pode reunir tanto um aspecto como outro, tanto o aspecto da facticidade da imposição de delimitações para a ação estratégica como o aspecto da validade do reconhecimento intersubjetivo das normas jurídicas, sem a qual 


\section{6}

estas não poderiam ter nenhuma força social integradora. As normas jurídicas propiciam a disposição para a sua obediência devido a esse duplo caráter: coerção fática e validade legítima. Ao mesmo tempo, elas põem à disposição dos seus destinatários o enfoque tanto da ação estratégica como o da ação comunicativa.

O desenvolvimento da moral universalista tem também o mesmo pano de fundo da racionalização e conseqüente diversificação de formas de vida. Porém, na exata medida em que a moral universalista pode se fundamentar inteiramente nos procedimentos formais da resolução discursiva de conflitos, ela apresenta três déficits estruturais, compensados pelo direito, a saber: uma indeterminação cognitiva a respeito da aplicação concreta de normas que anteriormente são fundamentadas em um alto nível de abstração; esse déficit é compensado pela facticidade da positivação jurídica, determinando as normas que valem como direito e os procedimentos judiciários para os confrontos de interpretação. Em segundo lugar, a moral universalista padece de uma incerteza motivacional, já que o que é considerado justo e obrigatório no nível da justificação das normas morais pode entrar em conflito com os próprios interesses particulares imediatos daquele que aceita o mandamento moral; tal incerteza motivacional é sanada pelo direito dado seu caráter impositivo, que generaliza e consolida expectativas de comportamento. Por fim, o preenchimento de exigências morais requer não só uma ação individual de conformidade, mas também uma ampla organização social que confere sentido a ela. Ou seja, as exigências morais só podem se realizar em estruturas institucionais que sustentam esforços cooperativos. Por sua vez, o direito se organiza ele próprio na forma de instituições que controlam as relações interpessoais, dando possibilidade, em grande escala, para a satisfação de princípios morais.

\section{II}

Todas essas considerações sobre a forma direito e sobre sua relação funcional com a moral se constituem, de um ponto de visto metodológico, no nível de uma teoria reconstrutiva da evolução social. Ao passar para a gênese lógica dos direitos fundamentais, essa operação reconstrutiva, por 
assim dizer, vertical, dá lugar a um experimento teórico abstrato, cujo intento é reconstruir horizontalmente, de maneira sincrônica, o sistema de direitos a fim de mostrar que os direitos subjetivos de liberdade de ação e os direitos políticos de participação política se pressupõem reciprocamente. Tal pressuposição ou interdependência entre os tipos de direitos fundamentais consolida-se na idéia de uma co-originariamente entre eles. Ou seja, um é condição de possibilidade do outro, embora não da mesma maneira.

A idéia fundamental é que o princípio da democracia, o qual detém força de legitimação, se deve ao "entrelaçamento do princípio do discurso e da forma direito” (HABERMAS, 1994, p. 155):

Esse entrelaçamento eu entendo como uma gênese lógica de direitos, que pode ser reconstruída passo a passo. Ela começa com a aplicação do princípio do discurso ao direito de liberdades subjetivas de ação em geral - constitutivo como tal da forma direito - e termina com a institucionalização jurídica das condições de um exercício discursivo da autonomia política, com a qual a autonomia privada posta [gesetzt] abstratamente de início pode ser configurada. Por isso o princípio da democracia só pode aparecer como cerne de um sistema de direitos. A gênese lógica desses direitos forma um processo circular, no qual o código do direito e o mecanismo para a geração de direito legítimo, isto é, o princípio da democracia, se constituem co-originariamente (HABERMAS, 1994, pp. 155-6).

O sistema de direitos que surge do entrelaçamento do princípio do discurso e da forma direito é apresentado em uma seqüência de cinco categorias de direitos fundamentais. As três primeiras categorias formam o código jurídico, pois determinam o status das pessoas de direito. Basicamente trata-se aqui dos direitos que garantem a maior medida possível de liberdades subjetivas de ação, dos direitos que estabelecem o status de membro de uma associação jurídica e, por fim, os direitos que garantem a possibilidade de postulação judicial e proteção jurídica das pessoas individuais (HABERMAS, 1994, pp. 155-6). Essas três primeiras categorias de direito garantem a autonomia privada dos sujeitos de direito unicamente no sentido de eles se reconhecerem mutuamente como destinatários da lei. Somente a quarta categoria permite que esses sujeitos de 


\section{8}

direito assumam também o status de cidadãos, isto é, de autores da própria ordem jurídica. Trata-se aqui dos direitos de participação igual nos processos de formação da opinião e da vontade. Essa quarta categoria, que garante a autonomia pública, tem um caráter reflexivo, já que permite interpretar e configurar concretamente em termos jurídicos tanto as primeiras categorias como a si própria. $\mathrm{Na}$ configuração política de todas essas categorias surge uma relação de implicação delas com a quinta categoria dos direitos fundamentais de bem-estar social, técnico e ecológico, isto é, direitos sociais, em sentido amplo, que permitem materialmente o exercício da autonomia privada e pública.

É de se observar que essas categorias são introduzidas em abstrato, sem um conteúdo particular, variável conforme o contexto sociopolítico. É somente com a quarta categoria que todos os direitos fundamentais recebem uma positivação jurídica concreta. Esse aspecto é importante para entender como as três primeiras categorias, que sustentam a autonomia privada, se relacionam com a quarta, que garante a autonomia pública.

Mas, antes de entrar nesse ponto central, é preciso se ater ao sentido da exposição da gênese. A passagem das três primeiras categorias para a quarta significa, para Habermas, um momento de transição de uma etapa abstrata para uma mais concreta, de uma etapa introduzida pelo teórico reconstrutivo para uma etapa em que os próprios cidadãos se entendem sobre a melhor interpretação e configuração dos direitos fundamentais. Portanto, significa a passagem do papel de destinatário para o papel de autor do direito positivo:

O andamento da exposição [Darstellung] vai do abstrato ao concreto, sendo que a concreção ocorre pelo fato de que, inicialmente, a perspectiva da exposição, trazida de fora, é internalizada pelo sistema exposto. Ora, esse sistema deve conter exatamente os direitos que os cidadãos têm de se adjudicar reciprocamente, se eles querem regular legitimamente seu convívio com os meios do direito positivo (HABERMAS, 1994, p. 155).

Para uma consideração metodológica, chama a atenção o fato de que a ordem da exposição implica uma mudança de perspectivas. A aplicação do princípio do discurso à forma do direito é feita, inicialmente, a partir de fora, da perspectiva de um teórico. Ou seja, "o teórico diz aos cidadãos que 
direitos eles teriam de se adjudicar reciprocamente, se eles querem regular legitimamente seu convívio com os meios do direito positivo." (HABERMAS, 1994, p. 160). É essa perspectiva externa que explicaria, em parte, o caráter abstrato das categorias dos direitos. É como se o teórico, no papel de um legislador prévio - a ser desmentido -, explicasse para os destinatários das leis a linguagem da direito, isto é, da forma direito e do código jurídico, unicamente no interior da qual é possível uma autolegislação.

No papel de autores, os cidadãos já não dispõem mais de nenhuma outra linguagem que não envolva as três primeiras categorias do direito. É nesse sentido que elas possibilitam a autonomia pública, sem restringila, ao mesmo tempo em que, por meio da autonomia pública, as três primeiras recebem uma positivação jurídica concreta. Com isso se tornaria compreensível a co-originariedade de autonomia pública e privada. Enquanto linguagem própria do direito, as categorias dos direitos privados não podem ser vistas "como direitos naturais ou morais, que apenas esperam ser colocados em vigor", nem podem "ser meramente instrumentalizados para fins de uma legislação soberana" (HABERMAS, 1994, p. 161). A idéia fundamental da co-originariedade se revela então na impossibilidade de que a autodeterminação política dos cidadãos se exercite no medium do direito, sem as três primeiras categorias do direito, já que, nesse caso, a própria participação política se daria sem a liberdade comunicativa necessária para que o princípio da democracia seja fonte de legitimação. Por sua vez, essas categorias não podem ser legitimadas e ganhar uma forma jurídica positiva, sem o direito de comunicação e participação no processo de formação da vontade.

O direito de comunicação e de participação é certamente instaurado com a quarta categoria, sendo institucionalizado e regulado juridicamente, de modo que os pressupostos de igualdade e simetria, inscritos nas condições de possibilidade de um discurso isento de dominação, recebem uma configuração jurídica determinada. Porém a liberdade comunicativa de tomar posição de sim ou não em relação às normas pressupõe também uma liberdade negativa de abster-se, a qual só pode ser garantida pela autonomia privada. Seguindo Klaus Günther, pode-se dizer que não haveria liberdade comunicativa se não houvesse também a liberdade negativa de não participar da comunicação pública, o que por sua vez é garantido pelas leis que sustentam a autonomia privada (cf. GÜNTHER, 1998, p. 236). 
Mas não é só nesse aspecto de garantir a própria lógica da liberdade comunicativa que a autonomia privada se torna condição da autonomia pública. Uma vez que esta última só pode se dar pelo medium do direito, ela necessita de um código jurídico primário com que se estabelece o sentido de um sujeito de direitos. Com isso, a autonomia privada juridicamente informada não pode ser deduzida inteiramente das condições procedimentais do discurso.

Desse modo, na construção da gênese lógica dos direitos fundamentais, nada é pressuposto antes da práxis política de autodeterminação, a não ser duas coisas: o princípio do discurso e o conceito de forma jurídica. A junção desses dois elementos forma imediatamente as três primeiras categorias constitutivas do código jurídico. Enquanto tais, essas três primeiras categorias não devem ser vistas como direitos naturais ou morais que comandam o exercício legislativo. Elas são antes condições necessárias que "só possibilitam o exercício da autonomia política." $\mathrm{Na}$ qualidade de condições de possibilidade elas "não restringem a soberania do legislador” (HABERMAS, 1994, p. 161-2).

Com a insistência sobre a impossibilidade de conferir um status moral ou natural aos direitos subjetivos de liberdade, Habermas parece querer evitar uma espécie de avatar da idéia de contrato social. Isso se torna mais claro quando perspectiva inicial do teórico reconstrutivo é relativizada. A recusa de ver os direitos fundamentais de liberdade como direitos naturais dados antes e determinando o legislador democrático tem como contrapartida o ancoramento histórico da reconstrução. Pois esses direitos só vêm à consciência em uma prática constituinte dada, de cujas regras intersubjetivamente estruturadas e juridicamente condicionantes os participantes têm um saber intuitivo:

Com uma versão do sistema de direitos encontrada da perspectiva de sua situação, os cidadãos apenas explicitam o sentido do empreendimento ao qual eles já se entregaram, tão logo decidiram regular legitimamente seu convívio através do direito. Um tal empreendimento pressupõe somente uma compreensão intuitiva do princípio do discurso e o conceito de forma direito (...). Ex post também a 'nossa' introdução teórica in abstracto dos direitos fundamentais se revela um artificio. Ninguém pode se atribuir o acesso a um sistema de direitos no singular, independentemente das 
interpretações que ele já encontra na história. 'O' sistema dos direitos não existe em pureza transcendental (HABERMAS, 1994, p. 163).

Tal como na reconstrução da ação comunicativa e das regras pragmáticas da linguagem, parte-se aqui de um saber intuitivo já operante em determinada práxis social, o qual é traduzido em um saber explícito e teórico. Para tanto, o teórico reconstrutivo tem de assumir a posição de um participante, a partir da qual ele pode compreender, já em si mesmo, que regras dão sentido a determinado construto simbólico. Busca-se descobrir o seu significado por meio das condições de validade pressupostas em todo ato de fala. Elas equivalem a condições de possibilidade em um sentido quase-transcendental. "Quase" porque se trata sempre de um experimento teórico que deve ser corroborado por pesquisas empíricas junto aos participantes concretos. Igualmente, em Facticidade e validade, Habermas entende a gênese como um "experimento teórico" cuja finalidade é uma "explicação do significado". Ou seja, trata-se de expor o que significa adotar a forma direito para a regulação legítima (isto é, por um princípio que exige o assentimento de todos) do convívio.

Porém esse experimento só é possível se se dispõe de uma reconstrução vertical, de uma teoria da evolução social, que explica, primeiramente, porque nenhuma outra fonte de legitimação está disponível na modernidade exceto o princípio do discurso, deduzido das condições da socialização lingüística, e, em segundo lugar, porque a moral pós-tradicional tem de ser completada pela forma direito para as finalidades da integração social. Em outros termos, a própria forma direito precisa de uma introdução à parte, já que ela, enquanto tal, não está inscrita nas condições da socialização lingüística da mesma maneira que a moral universalista ou o próprio princípio do discurso. É por isso que o teórico tem de dizer, no seu experimento, aos parceiros de direito quais direitos eles devem se atribuir reciprocamente caso utilizem a forma jurídica para a regulação legítima de seu convívio. Essa própria forma não pode ser deduzida do princípio do discurso, já que a reconstrução do seu significado tem de ser de outra ordem, justamente aquela da evolução social.

Com isso se pode esclarecer a perspectiva externa do teórico que diz aos cidadãos o código jurídico, já que ela pode induzir a pensar que se trata simplesmente da perspectiva de um observador, que apenas acom- 


\section{2}

panha de fora um jogo de linguagem, que ele descreve mas não compreende no sentido hermenêutico. Essa impressão é sugerida também por uma passagem, do início da seção III destinada a apresentar o sistema de direitos fundamentais, em que Habermas parece se filiar ao modo de operar do direito racional clássico. "Como no direito racional clássico, esses direitos devem ser introduzidos de início da perspectiva de um nãoenvolvido [Unbeteiligter]" (HABERMAS, 1994, p.151). Vimos que essa perspectiva é depois interiorizada dão logo os sujeitos do direito, os destinatários, adotem a posição de cidadãos, momento que corresponde ao passo da introdução dos direitos políticos. Porém não se pode tratar da perspectiva de um observador simplesmente pelo fato de que não cabe a este dizer aos envolvidos o que significa adotar o código jurídico como medium de organização social. No experimento teórico, esse ato de dizer de fora só pode significar que, de início, os envolvidos não podem derivar do princípio do discurso a forma direito. É o sentido desta que precisa ser esclarecido previamente. Por outro lado, há algo que os participantes já devem saber intuitivamente: a junção do princípio do discurso e da forma jurídica exige uma distribuição eqüitativa de direitos. Não a forma direito enquanto tal, mas o código jurídico tem de apresentar características legitimadoras derivadas das estruturas de simetria do discurso.

Acresce a isso o fato de que a posição do teórico é artificial, ele já está inserido em tradições constitucionais que lhe dão o horizonte de referência para a reconstrução da prática constituinte, isto é, de seu significado elementar. Para tal, porém, o exercício da abstração é indispensável. Ele precisa reduzir os elementos até contar com apenas dois: a forma do direito e o princípio do discurso, sendo que o primeiro só pode ser explicado por uma teoria da evolução social, e o segundo, a partir de uma reconstrução horizontal da socialização lingüística. A gênese lógica só pode contar com esses dois elementos mínimos.

Com isso, porém, não explicitamos inteiramente o sentido reconstrutivo dessa gênese. Vimos que, para Habermas, ela forma um "processo circular" e ao mesmo tempo explicita a co-originariedade do código jurídico (direitos de liberdade de ação e de autodeterminação) e o princípio de democracia (direitos de comunicação e participação). O círculo se deve a co-originariedade e a explicita ao mesmo tempo. Para Ingeborg Maus, as duas coisas demonstram a estrutura reflexiva do direito. Se por 
um lado é preciso dizer que "não um direito superior, mas o princípio da democracia engendra legitimidade, e a forma direito organiza o processo democrático, mas o direito legítimo é somente possível em virtude daquela última", por outro lado, cumpre observar que a "democracia verdadeira não é possível sem que esteja baseada no direito a iguais liberdades subjetivas e seus correlatos: todo ataque a esse direito viola seu próprio princípio organizacional” (MAUS, 2002, p. 92). Ou seja, o código jurídico pressupõe a democracia, e a democracia pressupõe o código jurídico. A violação dos direitos subjetivos pelo legislador democrático significa atacar os próprios fundamentos do procedimento democrático. Uma coisa remete a outra e vice-versa, ambas se pressupõe reciprocamente, uma é condição de possibilidade da outra. A reflexividade do direito se revela então no fato de que a legitimação democrática do direito positivo só pode se dar no medium do direito, isto é, a própria legislação, os próprios direitos de comunicação e participação são organizados juridicamente (MELO, 2005, p. 70).

Aqui não se trata de uma circularidade viciosa, no sentido dedutivo de pressupor no início o que está no fim. Não se pode tratar de um círculo teórico dedutivo devido à própria co-originariedade conceitual de direito e democracia. Porém é preciso começar a exposição por um lado ou por outro, pelos direitos fundamentais de liberdade que formam o código jurídico ou pelos direitos fundamentais de participação que constituem o princípio da democracia. O que passa ser decisivo, então, na interpretação da gênese é a porta de entrada no círculo. "Em outras palavras, de acordo com um dito bem-conhecido, não importa evitar o círculo mas entrar nele no lugar certo" (MAUS, 2002, p. 96). Para Maus, conforme o ponto em que se entra, tende-se mais a uma leitura liberal enfatizando a primazia dos direitos de liberdade, ou mais a uma leitura republicana, sublinhando a primazia da soberania popular. E o mesmo vale para as críticas respectivas em relação à exposição de Habermas.

O fato de a exposição da gênese lógica começar efetivamente pelos direitos subjetivos de liberdade pareceria, assim, contradizer toda a crítica habermasiana ao direito natural racional. Uma razão apontada para esse começo na ordem da exposição consiste na necessidade de apresentar a linguagem ou, como diz, Günther, a gramática profunda do processo deliberativo democrático (cf. GÜNTHER, 1994, p. 471). As três 
primeiras categorias de direitos fundamentais constituem o código jurídico sem o qual a democracia não poderia se organizar institucionalmente. Como uma gramática, no entanto, as categorias de direitos não restringiria a práxis deliberativa, elas não determinariam por si só um vocabulário para o legislador, que está livre para inclusive interpretar e configurar positivamente essa gramática. Dessa maneira, não se trata de restabelecer, para a produção legítima de direitos, uma subordinação da legislação aos princípios dos direitos liberais, já que eles mesmos são configurados em concreto pelo legislador.

Tal como uma gramática mínima que permite a geração de linguagens especiais, o código jurídico apenas possibilita mas não restringe as proposições dessas. No entanto, para evitar mal-entendidos, é preciso não perder de vista de que a reconstrução da "gramática" só é possível a partir do que foi gerado supostamente através dela. É da prática constituinte dada que se deve partir e não de um a priori inquestionável. Aqui se aplica também uma fundamentação "transcendental fraca”, sempre alicerçada em uma explicação do significado que tem como horizonte uma prática histórica determinada. Eis porque nunca existiu um código jurídico em "pureza transcendental". Além disso, essa gramática não é de natureza moral. Ela diz respeito a um princípio do discurso que reúne os pressupostos da fala isenta de dominação, o qual é, em si mesmo, neutro em relação à moral. Refere-se ainda às regras mínimas de uma forma direito que tampouco deriva ou se fundamenta moralmente. A reconstrução do sistema de direitos dispensa uma fundamentação moral, para abrir-se a uma práxis política cujos limites não são dados de uma vez para sempre, e somente no interior da qual os participantes podem colocar e interpretar suas próprias demandas.

Mas há mais uma razão para o começo da exposição se dar a partir da forma jurídica como tal. Essa razão é de ordem metodológica, como tentei sugerir desde o início. Uma vez que a reconstrução da gênese lógica do sistema de direitos é uma tentativa de explicitar o significado da práxis constituinte, ela opera desde o início com uma redução dessa práxis a dois elementos, o princípio do discurso, do qual os cidadãos dispõem um saber intuitivo, e o conceito de forma jurídica. O princípio do discurso, isoladamente, pode ser objeto de uma reconstrução interna, pela qual os participantes da práxis deliberativa podem reconhecê-lo 
como imanente a essa práxis. Isso porque o princípio do discurso se assenta nos pressupostos da socialização lingüística em geral. $\mathrm{O}$ mesmo não se passa com a forma jurídica, que não pode ser derivada das condições comunicativas da linguagem. Daí o início abstrato, externo, e por fim artificial de um teórico que diz aos destinatários do direito quais devem ser as categorias jurídicas fundamentais caso eles queiram regular democraticamente seu convívio por meio do direito. Porém, completado o círculo, e internalizado o significado da forma direito, qualquer ponto de entrada é possível, desde que não se perca de vista que a reconstrução tem de ser de duplo viés: soberania popular e direitos fundamentais de liberdade se condicionando reciprocamente.

1 Cf. MAUS, 2002, GÜNTHER, 1994. A interpretação de Ingeborg Maus é desenvolvida por MELO, 2005. Boa parte da investigação que se segue, ainda incipiente, depende desse trabalho de Melo, bem como do de Felipe Gonçalves (Cf. Liberdades em disputa: a reconstrução da autonomia privada na teoria crítica de Jürgen Habermas).

2 "O direito positivo, com que nos deparamos por assim dizer na modernidade como resultado de um processo de aprendizagem social, é recomendado como meio apropriado para estabilizar expectativas de comportamento em virtude de suas propriedades formais; para isso não parece haver nenhum equivalente funcional em sociedades complexas. A filosofia se coloca uma tarefa desnecessária quando ela quer demonstrar que organizar nosso convívio de acordo com o direito, ou seja, formar comunidades jurídicas em geral, não só é recomendado por motivos funcionais, mas que também é preceituado moralmente" (HABERMAS, 1994, p. 677). "Se a crítica se dirige contra a concepção dos direitos enquanto tal, a contraparte tem de propor, então, ou alternativas ao direito, como Marx o fez em sua época, ou pelo menos concepções de direito alternativas. Com esse tipo de questionamento eu não tenho nenhum problema, uma vez que não proponho nenhuma fundamentação normativa para a condição jurídica. (...) Por ora, não vejo um equivalente funcional para esse tipo de estabilização das expectativas de comportamento (mediante direitos subjetivos igualmente distribuídos). A esperança romântica - em um sentido não-pejorativo - do jovem Marx em um "definhamento" do direito dificilmente se cumprirá em sociedades complexas de nosso tipo" (HABERMAS, 1998, p. 346).

\section{Referências bibliográficas \\ GÜNTHER, K. 1994, “Diskurstheorie des Rechts oder liberales}


Naturrecht in diskurstheoretischem Gewande?". Kritische Justiz, BadenBaden, Bd. 27, Heft 4, S. 470-487.

. 1998. "Communicative freedom, communicative power, and jurisgenesis" in ROSENFELD, M. and ARATO, A., eds., Habermas on Law and Democracy. Critical Exchanges. University of California Press. HABERMAS, J. 1994. Faktizität und Geltung. Frankfurt am Main: Suhrkamp. 1998. Die Einbeziehung des Anderen. Frankfurt am Main: Suhrkamp.

KUPKA, TH. 1994. "Habermas' diskurstheoretische Reformulierung des klassischen Vernunftrechts". Kritische Justiz, Baden-Baden, Bd.27, Heft 4, S. 461-469.

LARMORE, 1993., "Die Wurzeln radikaler Demokratie”. Deutsche Zeitschrift für Philosophie, Berlin, Bd. 41, Heft 3, S. 321-327.

MAUS, I. 2002. "Liberties and popular sovereignty: On Jürgen Habermas's reconstruction of the system of rights. In BAYNES, K. and SCHOMBERG, R. eds., Discourse and democracy: Essays on Habermas's Between Facts and Norms. New York, State University of New York Press.

MELO, R. S. 2005. "Habermas e a estrutura 'reflexiva' do direito". Revista Direito GV, São Paulo, v. 1, n. 1, p. 67-78.

PINZANI, A. 2000. Diskurs und Menschenrecht - Habermas' Theorie der Rechte im Vergleich. Verlag Dr. Kovac, Boethiana. Forschungsergebnisse zur Philosophie, Bd. 43.

2001, “A teoria jurídica de Jürgen Habermas: entre funcionalismo e normativismo". Veritas, Porto Alegre, v. 46, n. 1, p. 19-28.

SCHEUERMAN, W. E. 2002."Between radicalism and resignation:

Democratic theory in Haberma's Between Facts and Norms". In BAYNES, K. and SCHOMBERG, R. eds., Discourse and democracy: Essays on Habermas's Between Facts and Norms. New York, State University of New York Press. 